\title{
Filmography
}

Films

Ada apa dengan Cinta, 2002, dir. Rudi Soedjarwo.

Aku ingin menciummu sekali saja, 2003, dir. Garin Nugroho.

Antara masa lalu dan masa sekarang, 2001, dir. Eddie Cahyono.

Arisan, 2003, dir. Nia Dinata.

Bad wolves, 2005, dir. Richard Buntario.

Bangungnya Nyai Roro Kidul, 1985, dir. Sisworo Gautama.

Berbagi suami (Love for share), 2006, dir. Nia Dinata.

Beth, 2001, dir. Aria Kusumadewa.

Blair Witch project, the, 1999, dir. Daniel Myrick, Eduardo Sànchez.

Bonex

Bukan isteri pilihannya, 1981, dir. Eduart P. Sirait.

Bulan tertusuk ilalang, 1994, dir. Garin Nugroho.

Buruan cium gue! (satu kecupan), 2004, dir. Findo Purwono.

Cemeng 2005 (The last prima donna), 1995, dir. N. Riantiarno.

Cinta dalam sepotong roti, 1991, dir. Garin Nugroho.

Coyote ugly, 2000, dir. David McNally.

Darah dan doa, 1950, dir. Usmar Ismail.

Death of a nation, 1994, dir. John Pilger.

Denias; Senandung di atas awan, 2006, dir. John de Rantau.

Desa di kaki bukit, 1972, dir. Asrul Sani.

Detik-detik revolusi, 1959, dir. Alam Surawidjaja.

Detik terakhir, 2005, dir. Nanang Istiabudi.

Di antara masa lalu dan masa sekarang, 2001, dir. Eddie Cahyono.

Djakarta 1966, 1982, dir. Arifin C. Noer.

Doea siloeman oeler poeti en item, 1934, dir. The Teng Cun.

Dr. Siti Pertiwi kembali ke desa, 1979, dir. Ami Prijono.

Dunia kami, duniaku, dunia mereka, 1999, dir. Adi Nugroho.

Ekskul, 2006, dir. Nayato.

(C) Katinka van Heeren, 2012 | DOI 10.1163/9789004253476_012

This is an open access chapter distributed under the terms of the Creative Commons

Attribution-Noncommercial-NonDerivative 3.0 Unported (CC-BY-NC-ND 3.0) License. 


\section{| Filmography}

El-Mariachi, 1992, dir. Robert Rodriguez.

Enam jam di Yogya, 1951, dir. Usmar Ismail.

Fatahillah, 1996, dir. Imam Tantowi, Chaerul Umam.

Fright night, 1985, dir. Tom Holland.

Ghostbusters, 1984, dir. Ivan Reitman.

Gie, 2005, dir. Riri Riza.

Harry Potter and the sorcerer's stone, 2001, dir. Chris Colombus.

Jaka Sembung sang penakluk, 1981, dir. Sisworo Gautama.

Janur kuning, 1979, dir. Alam Surawijaya.

Jelangkung, 2001, dir. Rizal Mantovani.

Joe turun ke desa, 1989, dir. Chaerul Umam.

Kado buat rakyat Indonesia, 2003, dir. Daniel Indra Kusuma.

Kado untuk ibu, 2005, prod. Syarikat Indonesia.

Kadosh, 1999, dir. Amos Gitai.

Kafir (Satanic), 2002, dir. Mardali Syarief.

Kameng gampoeng nyang keunong geulawa, 1999, dir. Aryo Danusiri.

Kepada yang terhormat titik 2, 2002, dir. Dimas Jayasrana.

Kereta api terakhir, 1981, dir. Mochtar Soemodimedjo.

Kiamat sudah dekat, 2003, dir. Deddy Mizwar.

Kisah cinta Nyi Blorong, 1989, dir. Norman Benny.

Kuldesak, 1997, dir. Mira Lesmana, Riri Riza, Rizal Mantovani, Nan Achnas.

Kutunggu di sudut Semanggi, 2004, dir. Lukmantoro.

Lahir di Aceh, 2003, dir. Ariani Djalal.

Last communist, the (Lelaki komunis terakhir), 2006, Amir Muhammad.

Lastri; Suara perempuan korban tragedi 1965.

Lentera merah, 2006, dir. Hanung Bramantyo.

Lebak membara, 1982, dir. Imam Tantowi.

Lung boonmee raluek chat (Uncle Boonmee who can recall his past lives), 2010, dir. Apichatpong Weerasethakul.

Marsinah, 2002, dir. Slamet Rahardjo.

Mass grave, 2001, dir. Lexy Rambadeta.

Mistik (punahnya rahasia ilmu Iblis leak), 1981, dir. Tjut Djalil.

Novel tanpa huruf R, 2003, dir. Aria Kusumadewa.

Opera Jawa, 2006, dir. Garin Nugroho.

Operasi X, 1968, dir. Misbach Yusa Biran.

Pena pena patah, 2002, dir. Sarjev Faozan. 
Penumpasan pengkhianatan G30S/PKI, 1982, dir. Arifin C Noer.

Penumpasan sisa-sisa PKI Blitar Selatan (Operasi Trisula), 1986, dir. BZ Kadaryono.

Pembalasan Ratu Laut Selatan, 1988, dir. Tjut Djalil.

Penyair negeri Linge, 2000, dir. Aryo Danusiri.

Perawan di Sektor Selatan, 1971, dir. Alam Surawidjaja.

Perempuan di wilayah konflik, 2002, dir. Gadis Arivia.

Perempuan; Kisah dalam guntingan, 2007, dir. Ucu Agustin.

Peronika, 2004, dir. Bowo Leksono.

Peti mati (The coffin), 2003, dir. Mardali Syarief.

Puisi tak terkuburkan (A poet), 1999, dir. Garin Nugroho.

Pulp fiction, 1994, dir. Quentin Tarantino.

Putri Kunti'anak, 1988, dir. Atok Suharto.

Ramadhan dan Ramona, 1992, dir. Chaerul Umam.

Ranjang Setan, 1986, dir. Tjut Djalil.

Ratu ular, 1972, dir. Lilik Sudjio.

Rembulan dan matahari, 1979, dir. Slamet Rahardjo.

Revolusi harapan, 1997, dir. Nanang Istiabudi.

Sangat laki-laki, 2004, dir. Fajar Nugroho.

Satria bergitar, 1983, dir. Nurhadie Irawan.

Satu nyawa dalam denting lonceng kecil, 2002, dir. Abiprasidi.

Saur sepuh (Satria Madangkara), 1988, dir. Imam Tantowi.

Schindler's list, 1993, dir. Steven Spielberg.

Sembilan wali, 1985, dir. Djun Saptohadi.

Serangan fajar, 1982, dir. Arifin C. Noer.

Sinengker, 2007, dir. Aprisiyanto, 2007.

Si Pitung beraksi kembali, 1981, dir. Lie Soen Bok.

Snatch (Dukot (Desaparecidos)), 2009, dir. Joel Lamangan.

Soerabaia 45, 1990, dir. Imam Tantowi.

Soul, the, 2003, dir. Nayato Fio Nuala.

Student movement in Indonesia, 1998, dir. Tino Saroengallo.

Sunan Kalijaga, 1983, dir. Sofyan Sharna.

Sunan Kalijaga E Syeh Sitijenar, 1985, dir. Sofyan Sharna.

Thirteen, 2003, dir. Catherine Hardwick.

Titian serambut dibelah tujuh (The narrow bridge), 1982, dir. Chaerul Umam.

Titik hitam, 2002, dir. Sentot Sahid. 
| Filmography

Topeng kekasih, 2000, dir. Hanung Bramantyo.

True lies, 1994, dir. James Cameron.

Tusuk jelangkung, 2003, dir. Dimas Djayadiningrat.

Virgin, 2004, dir. Hanny Saputra.

Television films

Bang bang you're dead, 2002, dir. Guy Ferland.

Bukan sekadar kenangan Kasih ibu selamanya Pedang keadilan (Indosiar).

Terjebak, 1996, dir. Dedi Setiadi.

Television series

Anak Baru Gedhe (RCTI)

Astaghfirullah (SCTV)

Azab Ilahi (Lativi)

Baywatch (RCTI; first broadcast on NBC, United States of America)

Beverly Hills 90210 (RCTI; first broadcast on Fox, United States of America)

Ceramah Ramadhan AA Gym (Trans TV)

Cowok cowok keren (RCTI)

Dua dunia (Indosiar)

Dunia lain (Trans TV)

Esmeralda (SCTV; first broadcast on Televisa Mexico)

Gema Ramadhan (SCTV)

Gema takdir (SCTV)

Hantu sok usil (SCTV)

Hidayah (Trans TV)

Indahnya kebersamaan (SCTV)

Insyaf (Trans TV)

Janda kembang (SCTV)

Jin dan Jun (RCTI)

Kembalinya Si Manis Jembatan Ancol (RCTI)

Kisah2 teladan (Indosiar)

Kismis (RCTI)

Kismis; Arwah penasaran (RCTI)

Layar tancep (Lativi)

Manajemen qulbu spesial Ramadhan (RCTI)

Melrose Place (SCTV; first broadcast on Fox Network, United States of America) 
Membuka pintu langit (SCTV)

Misteri (Anteve)

Misteri sinden (RCTI)

Nah ini dia (SCTV)

O seraam (Anteve)

Pemburu hantu (Lativi)

Percaya nggak percaya (Anteve)

Rahasia Ilahi (TPI)

Sambut Ramadhan (SCTV)

Sebuah kesaksian (Lativi)

Sentuhan qolbu Ramadhan (TPI

Si Manis Jembatan Ancol (RCTI)

Takdir Ilahi (TPI)

Taubat (Trans TV)

Three in one (SCTV)

Tuyul dan Mbak Yul (RCTI)

VIP (RCTI, American syndicated television series) 